\title{
Medulloblastoma: advances and challenges
}

\author{
Martine F. Roussel ${ }^{1 *}$ and Giles Robinson ${ }^{2}$
}

Addresses: ${ }^{1}$ Department of Tumor Cell Biology, Danny Thomas Research Center, MS\# 350, St. Jude Children's Research Hospital, 262 Danny Thomas Place, Memphis, TN 38105, USA; ${ }^{2}$ Department of Oncology, St. Jude Children's Research Hospital, 262 Danny Thomas Place, Memphis, TN 38105, USA

*Corresponding author: Martine F. Roussel (martine.roussel@stjude.org)

FI000 Biology Reports 20II, 3:5 (doi:I0.34I0/B3-5)

This is an open-access article distributed under the terms of the Creative Commons Attribution-Non Commercial License (http://creativecommons.org/licenses/by-nc/3.0/legalcode), which permits unrestricted use, distribution, and reproduction in any medium, provided the original work is properly cited. You may not use this work for commercial purposes.

The electronic version of this article is the complete one and can be found at: http://fl000.com/reports/b/3/5

\begin{abstract}
Medulloblastoma, a cancer of the posterior fossa, is the most common malignant brain tumor in children. Although $80 \%$ of patients with average-risk medulloblastoma are cured, their quality of life is often compromised by treatment-related side effects. Recently, molecular and genomic studies have shown medulloblastoma to be a heterogeneous disease made up of distinct disease subtypes. The importance of this finding is that response to therapy appears to be subtype-specific. Nevertheless, most patients are still treated according to risk stratification methods based on the clinically defined presence or absence of disseminated disease, which take no account of these newly defined subtypes. The potential, however, to vastly reduce therapy-mediated toxicity to patients with tumor subtypes that have good outcomes, while improving therapy through targeting for the poor responders, is now palpable. Critical to this effort will be the ongoing refinement of our understanding of medulloblastoma subgroups at the molecular level and the development of mouse models that faithfully recapitulate tumor subtypes.
\end{abstract}

\section{Introduction and context}

Each year, around 1,000 children (mostly between the ages of 3 and 7 years old) worldwide will develop medulloblastoma [1]. Although advances in neurosurgery, radiation oncology, and chemotherapy have led to dramatic increases in survival rates, $20 \%$ percent will die. For those that survive, current treatments have significant morbidity. Surgery carries a high risk of the development of postoperative cerebellar mutism [2]. Radiation therapy leads to a broad spectrum of cognitive and endocrine impairments [3]. Chemotherapy at the current doses designated to treat medulloblastoma frequently results in hearing loss, infertility, and neuropathies [4].

Not surprisingly, treatment failures have been noted to be higher in children whose cancer has metastasized at diagnosis $[4,6]$. Risk stratification is used to attempt to identify the severity of the disease and hence how intense the therapy should be, and consequently, clinical trials apply higher intensity treatment to the patients with disseminated disease than those without. Nevertheless, metastasis is not the only feature associated with outcome. Medulloblastomas have also long been recognized by pathologists to have differing histologic characteristics and there are five variants recognized in the 2007 World Health Organization classification of central nervous system tumors [7]. Most of these variants can be categorized into three major pathologic groups: the classic, the nodular desmoplastic, and the large-cell anaplastic $[5,7]$. When outcome is measured accordingly, the large-cell anaplastic medulloblastomas fare the worst and the desmoplastics the best. Furthermore, if one uses immunohistochemical staining to identify those tumors that localize beta-catenin (CTNNB1) to the nucleus, another subgroup of classic histology emerges. These patients, with nucleopositive CTNNB1 tumors, have near complete survival on current therapy and, therefore, carry the most favorable prognosis $[8,9]$. Curiously, these tumors have been found to occur in older children and adolescents. Nodular desmoplastic tumors, on the other hand, generally occur in younger children $[8,9]$. The sum of these findings suggests that there are subtypes 
of medulloblastoma that have inherent differences on the cellular level. Unfortunately, the histologic diagnosis of medulloblastoma is complicated by individual pathologists interpreting the histology differently and difficulties in defining subtle features like anaplasia. Improvements in technology have allowed research to delve into tumors at the molecular level, in order to find a more incontrovertible system for diagnosing medulloblastoma.

\section{Molecular characterization}

What has emerged is a series of studies that identify four to six subgroups of medulloblastoma on the basis of molecular differences [10-12]. Despite the disparity in the number of subtypes, there is a lot of common ground among the studies. All describe a subtype with aberrant Sonic Hedgehog pathway signaling (often PTCH1 mutations), which has a high incidence amongst desmoplastic tumors [10-12]. Another subtype has aberrant signaling in the Wingless (WNT) pathway (frequently CTNNB1 mutations), a classic histology that commonly affects older children [5,10-12]. Additionally, a less favorable subtype emerged from the latest studies [12], which associates MYC overexpression and amplification with poor prognostic features (i.e., high prevalence of metastatic disease and large-cell anaplastic histology).

All these subtypes have correlations with the histologic variants (i.e., the Sonic Hedgehog subtype are largely desmoplastic tumors and the MYC subtype are frequently large-cell anaplastic tumors), so the molecular profiling of these tumors should reduce the inconsistencies between different pathologists' interpretations. Signaling pathways that promote growth (e.g., Sonic Hedgehog, WNT, Notch, Hippo, and IGF/PI3K) or suppress proliferation (e.g., BMP2, BMP4, and BMP7) can now be analyzed by subtype $[13,14]$. Furthermore it is likely that tumor suppressors, oncogenes, microRNAs, and epigenetic mediators will be identified as we continue to analyze the molecular profile and conduct next generation sequencing on an increasing number of tumors. Such molecular analysis of tumors should ultimately allow us to use targeted therapies directed at the defective pathway.

\section{The cellular origin of medulloblastoma subgroups}

Recent studies have suggested that medulloblastomas arise from neuronal stem/progenitor cells in the cerebellum as a result of defects in genes that regulate normal growth and differentiation [5]. As such, identifying the cell of origin of these embryonal tumors is also an intense ongoing area of investigation. For example, granule neuron progenitors (GNPs), a type of progenitor cell in the brain, rely on the mitogen Sonic Hedgehog binding with the transmembrane receptor PTCH for their expansion [15], and it was recently demonstrated that the subgroup of medulloblastomas with mutations that lead to constitutive activation of this pathway originate from GNPs [16]. Similarly, albeit in a mouse model, medulloblastomas with mutated Ctnnb1, which resemble the human WNT subgroup [17], were shown to arise from a distinct germinal zone of the hindbrain called the lower rhombic lip that develops into structures within the brainstem [17]. The finding that the two best-known subgroups originate from different developmental zones of the hindbrain further supports the hypothesis that different subgroups of medulloblastoma arise from different progenitors. In addition, these progenitors differ from each other as they appear to be uniquely susceptible to disruption by different mutations. Unfortunately, despite great strides into the molecular analysis of the disease, it is still unclear from which cells the other subgroups of medulloblastomas arise.

\section{Targeted therapies}

Our increasing understanding of Sonic Hedgehog signaling has led to the discovery and development of multiple mouse models with mutations that disrupt this pathway. These models, in turn, have led to the discovery of drugs that inhibit proteins activated by this pathway. Because these compounds have worked remarkably well to suppress medulloblastomas in mouse models [18], they have recently entered clinical trials [19]. Early results are promising even in highly aggressive relapsed tumors [19]. Unfortunately, these effects are not all permanent and even highly responsive tumors appear to be able to generate resistance when the compounds are given as monotherapy [20]. Like most chemotherapy, remission may only become sustainable when given as a part of multiregimen treatment plan.

\section{Future directions}

The information we gain from the molecular analysis of medulloblastomas should enable physicians to better target therapies $[21,22]$. Currently, one can envision how early identification of the WNT subgroup at diagnosis could be used to stratify these patients to a less aggressive treatment arm, thus lessening the negative secondary effects of treatment. Also, if proven safe, it will not be long before inhibitors of Sonic Hedgehog signaling can be given to patients with Sonic Hedgehog-subtype tumors as part of their therapy. We remain, however, desperate to find better therapy for all patients, especially those who are succumbing to high risk aggressive tumors. This improvement in therapy can only come from an improved understanding of the disease itself and every effort needs to be made to increase our knowledge 
of medulloblastoma at the molecular level. Understandably, the molecular defect in all the medulloblastoma subtypes will enable us to develop new and improved mouse models that recapitulate the human disease, which in turn will lead to targeted treatment with the potential to cure all the forms of this once devastating disease.

\section{Abbreviations}

BMP2, bone morphogenetic protein 2; CTNNB1, catenin (cadherin-associated protein) beta 1; IGF/PI3K, insulinlike growth factor/phosphatidylinositol 3-kinase; GNP, granule neuron progenitor; PTCH1, patched 1; WNT, wingless.

\section{Competing interests}

The authors declare that they have no competing interests.

\section{Acknowledgments}

We would like to thank Daisuke Kawauchi and Brian Murphy for critically reading this report. MFR is currently funded in part by the National Institutes of Health (grants CA-096832 and CA-21765), and a James McDonnell Foundation Research Award. MFR and GR are also funded in part by the American Lebanese Syrian Associated Charities (ALSAC) of St. Jude Children's Research Hospital.

\section{References}

I. Rutkowski S, Cohen B, Finlay J, Luksch R, Ridola V, ValteauCouanet D, Hara J, Garre ML, Grill J: Medulloblastoma in young children. Pediatr Blood Cancer 2010, 54:635-7.

2. Robertson PL, Muraszko KM, Holmes EJ, Sposto R, Packer RJ, Gajjar A, Dias MS, Allen JC; Children's Oncology Group: Incidence and severity of postoperative cerebellar mutism syndrome in children with medulloblastoma: a prospective study by the Children's Oncology Group. J Neurosurg 2006, I05(6 Suppl): 444-51.

3. Palmer SL, Reddick WE, Gajjar A: Understanding the cognitive impact on children who are treated for medulloblastoma. J Pediatr Psychol 2007, 32: 1040-9.

4. Gajjar A, Chintagumpala M, Ashley D, Kellie S, Kun LE, Merchant TE, Woo S, Wheeler G, Ahern V, Krasin MJ, Fouladi M, Broniscer A, Krance R, Hale GA, Stewart CF, Dauser R, Sanford RA, Fuller C, Lau C, Boyett JM, Wallace D, Gilbertson RJ: Risk-adapted craniospinal radiotherapy followed by high-dose chemotherapy and stemcell rescue in children with newly diagnosed medulloblastoma (St Jude Medulloblastoma-96): long-term results from a prospective, multicentre trial. Lancet Oncol 2006, 7:8I3-20.

5. Gilbertson RJ, Ellison DW: The origins of medulloblastoma subtypes. Annu Rev Pathol 2008, 3:34I-65.

6. Finlay JL, Erdreich-Epstein A, Packer RJ: Progress in the treatment of childhood brain tumors: no room for complacency. Pediatr Hematol Oncol 2007, 24:79-84.

7. Louis DN, Ohgaki H, Wiestler OD, Cavenee WK, Bruger PC, Jouvet A, Scheithauer BW, Kleihues P: The 2007 WHO classification of tumours of the central nervous system. Acta Neuropathol I | 4:97-109.

8. Ellison DW, Onilude $\mathrm{OE}$, Lindsey JC, Lusher ME, Weston CL, Taylor RE, Pearson AD, Clifford SC; United Kingdom Children's Cancer Study Group Brain Tumour Committee: beta-Catenin status predicts a favorable outcome in childhood medulloblastoma: the United Kingdom Children's Cancer Study Group Brain Tumour Committee. J Clin Oncol 2005, 23:795I-7.

9. Fattet $S$, Haberler $C$, Legoix $P$, Varlet $P$, Lellouch-Tubiana $A$, Lair $S$, Manie E, Raquin MA, Bours D, Carpentier S, Barillot E, Grill J, Doz F, Puget S, Janoueix-Lerosey I, Delattre O: Beta-catenin status in paediatric medulloblastomas: correlation of immunohistochemical expression with mutational status, genetic profiles, and clinical characteristics. J Pathol 2009, 218:86-94.

10. Thompson MC, Fuller C, Hogg TL, Dalton J, Finkelstein D, Lau CC, Chintagumpala M, Adesina A, Ashley DM, Kellie SJ, Taylor MD, Curran T, Gajjar A, Gilbertson RJ: Genomics identifies medulloblastoma subgroups that are enriched for specific genetic alterations. J Clin Oncol 2006, 24:1924-31.

II. Kool M, Koster J, Bunt J, Hasselt NE, Lakeman A, van Sluis P, Troost D, Meeteren NS, Caron HN, Cloos J, Mrsić A, Ylstra B, Grajkowska W, Hartmann W, Pietsch T, Ellison D, Clifford SC, Versteeg R: Integrated genomics identifies five medulloblastoma subtypes with distinct genetic profiles, pathway signatures and clinicopathological features. PLoS One 2008, 3: e3088.

12. Northcott PA, Korshunov A, Witt H, Hielscher T, Eberhart CG, Mack S, Bouffet E, Clifford SC, Hawkins CE, French P, Rutka JT, Pfister S, Taylor MD: Medulloblastoma Comprises Four Distinct Molecular Variants. J Clin Oncol 2010, [Epub ahead of print].

FI000 Factor 8

Evaluated by Martine Roussel 02 Feb 2011

13. Roussel MF, Hatten ME: Cerebellum: development and medulIoblastoma. Curr Top Dev Biol 2010, in press.

14. Ellison DW: Childhood medulloblastoma: novel approaches to the classification of a heterogenous disease. Acta Neuropathol 2010, I20:305-16.

15. Vaillant C, Monard D: SHH pathway and cerebellar development. Cerebellum 2009, 8:291-30I.

16. Behesti $\mathrm{H}$, Marino S: Cerebellar granule cells: insights into proliferation, differentiation, and role in medulloblastoma pathogenesis. Int J Biochem Cell Biol 2009, 4 I:435-45.

17. Gibson P, Tong $Y$, Robinson G, Thompson MC, Currle DS, Eden C, Kranenburg TA, Hogg T, Poppleton H, Martin J, Finkelstein D, Pounds S, Weiss A, Patay Z, Scoggins M, Ogg R, Pei Y, Yang ZJ, Brun S, Lee Y, Zindy F, Lindsey JC, Taketo MM, Boop FA, Sanford RA, Gajjar A, Clifford SC, Roussel MF, McKinnon PJ, et al.: Subtypes of medulloblastoma have distinct developmental origins. Nature 2010, 468:1095-9.

18. Romer J, Curran T: Targeting medulloblastoma: small-molecule inhibitors of the Sonic Hedgehog pathway as potential cancer therapeutics. Cancer Res 2005, 65:4975-8.

19. Rudin CM, Hann CL, Laterra J, Yauch RL, Callahan CA, Fu L, Holcomb T, Stinson J, Gould SE, Coleman B, LoRusso PM, Von Hoff DD, de Sauvage FJ, Low JA: Treatment of medulloblastoma with hedgehog pathway inhibitor GDC-0449. N Engl J Med 2009, 361:1 173-8.

FI000 Factor 8

Evaluated by Martine Roussel 02 Feb 2011

20. Yauch RL, Dijkgraaf GJ, Alicke B, Januario T, Ahn CP, Holcomb T, Pujara K, Stinson J, Callahan CA, Tang T, Bazan JF, Kan Z, Seshagiri S, Hann CL, Gould SE, Low JA, Rudin CM, de Sauvage FJ: Smoothened mutation confers resistance to a Hedgehog pathway inhibitor in medulloblastoma. Science 2009, 326:572-4.

FI000 Factor 6

Evaluated by Jeffrey Benkovic 0I Mar 2010

21. Huse JT, Holland EC: Targeting brain cancer: advances in the molecular pathology of malignant glioma and medulloblastoma. Nat Rev Cancer 2010, 10:319-31.

22. Hadjipanayis CG, Van Meir EG: Brain cancer propagating cells: biology, genetics and targeted therapies. Trends Mol Med 2009, 15:519-30. 